\title{
The Reform and Practice of Computer Experimental Teaching Model
}

\author{
Kai ZHANG \\ Institute of Technology, Tianjin University of Finance and Economics, \\ Tianjin, China, 300222
}

Keywords: reform; computer experimental teaching; innovation

\begin{abstract}
The computer experimental teaching has become an important part in the system of the innovation in higher education. And it plays an indispensable role in teaching system of the computer specialty. The article analyzes the current situation of the experimental teaching in computer specialty, and puts forward the reform measures and methods.
\end{abstract}

\section{Introduction}

Experimental teaching plays an important role in fostering students' practical ability, innovation and scientific literacy and so on. Theoretical teaching cannot replace experimental teaching in computer specialty. However, in the present teaching, teachers generally pay attention to construction of the theoretical foundation and knowledge systems. The attention to the training of students' practical abilities is inadequate and experimental teaching is relatively weak. The training mode of traditional teaching which attach importance to knowledge and class and ignore abilities and experiments cannot meet the needs of society. We have to establish the concept which ability training is the core of experimental teaching. We have to establish diversified experimental teaching mode, construct high-quality experimental teaching team. In addition, environment with advanced equipment, resource sharing, service opening experiment teaching is also important. The reform of computer experiment teaching is imperative.

\section{Analysis of current situation of computer experiment teaching activity}

The experimental teaching in colleges and universities is the effective way to understand the theoretical knowledge, form the knowledge system, improve the comprehensive practice ability and cultivate the innovation consciousness. Traditional experimental teaching mode can't meet the social demands for the college students' ability. There is a phenomenon of the serious disconnection between theory and practice. The existing problems are mainly manifested in the following aspects:

The concept of thinking little of experiment in many colleges and universities is still common in the concept of advanced teaching. The experimental class as a byproduct of curriculum theory, even in the final examination scores of experimental class accounted for only $10 \%$ of course final grade, which will undoubtedly hurt the teacher's teaching enthusiasm, and enable students to ignore experiment course.

The experimental teaching of the experimental teaching material is old, the experimental equipment is backward, and the pace of the development of the advanced technology is not followed. The experiments are mostly verified and duplicated. Some teachers still use textbooks which are published a few years ago or even earlier in the experiment teaching.Teachers provide experimental instructions and procedures of the experiment and students can only passively accept the experiment content, repeat each step mechanically and hand in the report. Students' initiative and enthusiasm in study is restricted. With time goes by, this method will lead to low capacity of practice, finding problems and solving problems.

At present, many colleges and universities have the phenomenon that the experimental teaching team is weak, and the experimental teaching level is difficult to improve. For a long time, teachers in the university experiment and technicians in the laboratory are considered as teaching assistant. Their status and role is not stressed, leading to experimental classes are in a secondary position. Unreasonable structure of the experimental teacher, lack of professional experimental teachers with 
highly educational background and professional title seriously affect the experimental teaching effect, which restricts the improvement of the experimental teaching level. The innovation ability of students can't be well trained. And even to some extent, it also kills the development of students' innovation ability. Experimental teaching is in urgent need of reformation.

\section{Reform experiment teaching management system}

\section{Optimize the experimental center management mode}

University laboratory is the important base for experiment teaching and scientific research. At present, the reform and development of experimental teaching is confined by the existing management system of many university laboratories .We must carry out the reformation of laboratory management system. We have to strengthen the autonomy of laboratory management organizations, establish specialized functional management agencies, and break the two levels of the school management system. We should establish the school level experimental center according to the subject classification. They are responsible for the establishment and improvement of the experimental teaching system of school .At the same time, laboratory management departments are ought to organize experimental and technical personnel training, organize and implement quality monitoring of experiment teaching, organize the projects' research and development and deal with laboratory equipment maintenance work. Specialized laboratory management transform traditional decentralized management to school's centralized management, which will realize intensive management of laboratory resources and reasonable allocation of laboratory personnel. Also, it can form the scale benefit, improve the utilization rate of the experimental apparatus and comprehensively improve the quality of teaching.

\section{Strengthen the construction of experimental teachers}

For a long time, the experimental technical personnel in universities is regarded as the teaching staff, which means it is in the secondary, subordinate status. Ignorance in salary, promotion, training and other aspects result in weak team of laboratory faculty. Colleges should adjust the experimental technology team, optimize the title and academic structure, enrich the experiment teaching and technical team with experienced teachers, and improve the experimental teaching technology. Reasonable laboratory teacher team structure should be a trapezoidal structure. The bottom of team is consisted of young doctor and graduate students. The central areas should be young and middle-aged academic backbone with higher academic level. Upper areas should have academic leaders with certain academic influence of composition. Thus, it will form a reasonable structure of the trapezoidal experiment teaching team with the number of people gradually decreasing and the academic level gradually increasing by layer.

\section{Strengthen the construction of computer experimental course system}

Experimental teaching is a complete organic system, including the course system of the overall structure, curriculum type and content. Only when various elements are balanced can we achieve overall optimization effect. According to the formation mechanism and the patter of the talents training objective and the teaching objective, attention must be paid to experimental teaching and theoretical teaching and supporting. In order to deepen the experiment content and course system reform, computer experiment courses should be aimed to the different characteristics of each stage of students. Experiment teaching syllabus should be designed to focus on cross fusion between the courses. In order to design the syllabus, colleges should analysis the intersection of related courses and abstract similarities between professional courses. The contents of the experiment should be clear, operable and have the characteristics of phase integrity, and different stages can be independently practice in different courses.

And there is not a universal model in construction of the system of experimental teaching in colleges. Cultivating the students' innovative spirit and practical ability should be the main line. Exploring and establishing diversified experimental teaching system is based on closely combined with the characteristics of the university school running position, discipline, personnel training and 
other characteristics of the characteristics of the requirements.

\section{Diversified teaching method reform}

According to the concept and innovation of modern education, the teachers should actively explore new technology, new methods and new means in the teaching process. During the actual teaching process, the full use of modern network, information, multimedia technology and rich teaching method would highlight teaching atmosphere. The establishment of Student Centre, the introduction of teaching, interactive and open experiment teaching method should be discussed. For example, in open teaching experiment, we should offer to students free proposition during the experiment, throughout the experiment by students completed independently designed, experimental open content, open of experimental time, experimental environment and opening up. The purpose of open experimental teaching is to exercise and improve the students' practical ability and comprehensive quality. In the process of carrying out the experiment, we can take the actual situation of the teaching method to carry out the experimental teaching, and exert the advantages of various experimental platforms. We should create a comprehensive experimental platform for students, the experimental hardware platform, software platform, simulation platform and virtual experiment platform of organic combine. We should realize different platform of experimental teaching, which can better cultivate students' practical ability.

\section{Improve the assessment and evaluation system of experimental teaching}

Different assessment methods need to be done depend on different types of experiments. For instance, as some basic experiments focus on whether students can have fundamental notions on experiments principle and do some basic practices, assessments of this kind of experiments should concentrate on spot check and the quality of experiment report. While for some designing and comprehensive project, students can do some demonstrations and comment of their own projects and assessment should concentrate on the reference items of mission indicators. Besides, students and tutors can present some designs in some creative experiments, while the experiments should be completed by students only. At last, the paper reports of scientific research should be handled to tutors.

\section{Conclusion}

College experiment teaching and management is a systematic project and an essential part of education reform. With the advent and development of reform in education, there will be more new subjects for us to study further. So, we need to do more experiments on teaching system and methods in order to improve the quality of the whole teaching system.

\section{References}

[1] Liu Lun, Research on the reform of open computer experiment. computer education, 2013.02

[2] Sun Yimin, Research status of higher education experiment system in China. Journal of Shandong Jianzhu University, 2012.09

[3] Liu Yinping, Exploration on diversified experimental teaching mode, electronic teaching journal, 2009.08

[4] Liu Xia, Chen Liu,Problems and Countermeasures of experimental teaching in Colleges and universities, China Power Education, 2014.11

[5] Tian Hong. Problems and Countermeasures of experimental teaching in Colleges and Universities: [J]. experimental science and technology, 2014.02 